University of Wollongong

Research Online

Australian Institute for Innovative Materials -

Papers

Australian Institute for Innovative Materials

$1-1-2015$

\title{
A bi-layer TiO2 photoanode for highly durable, flexible dye-sensitized solar cells
}

Jianjian Lin

University of Wollongong, j1824@uowmail.edu.au

Yong Peng

Monash University

Alexander Pascoe

Monash University

Fuzhi Huang

Monash University

Yi-Bing Cheng

Monash University

See next page for additional authors

Follow this and additional works at: https://ro.uow.edu.au/aiimpapers

Part of the Engineering Commons, and the Physical Sciences and Mathematics Commons

Research Online is the open access institutional repository for the University of Wollongong. For further information contact the UOW Library: research-pubs@uow.edu.au 


\title{
A bi-layer TiO2 photoanode for highly durable, flexible dye-sensitized solar cells
}

\begin{abstract}
Low-temperature processing of dye-sensitized solar cells (DSCs) [B. Oregan, M. Grätzel, Nature, 1991, $353,737]$ is crucial to enable their commercialization with low-cost plastic substrates. Much of the previous work in this area has focused on mechanical compression of premade particles on plastic substrates; however, many reported that this technique did not yield sufficient interconnections for high charge carrier transport. Herein, we present bi-layer photoanodes that incorporate microstructured $\mathrm{TiO}_{2}$ sea-urchin-like assemblies, composed of high-aspect-ratio single crystalline nanoribbons, i.e., twodimensional subunits, which were deposited onto a nanoparticle layer (commercial P25), with a 5.6\% conversion efficiency realized. We demonstrate that this Mesoporous Hierarchical Anatase $\mathrm{TiO}_{2}(\mathrm{MHAT})$ nanostructure is beneficial due to its enhanced dye loading as well as enhanced light scattering. Importantly, we also show the benefits of a bi-layer structure where the nanoribbons penetrate into the nanoparticle layer (P25) after cold isostatic pressing (CIP), resulting in improved adhesion between the MHAT top layer and the P25 under layer on the indium tin oxide-coated polyethylene naphthalate (ITOPEN) substrate, leading to improved mechanical stability and durability, efficient electron transfer pathways, and ultimately, higher solar-to-electric conversion efficiencies. This journal is
\end{abstract}

\section{Keywords}

flexible, sensitized, bi, layer, tio2, photoanode, solar, highly, cells, durable, dye

\section{Disciplines}

Engineering | Physical Sciences and Mathematics

\section{Publication Details}

Lin, J., Peng, Y., Pascoe, A. R., Huang, F., Cheng, Y., Heo, Y., Nattestad, A., Seung, W., Kim, S., Yoon, H., Kim, S., Yamauchi, Y., Dou, S. Xue. \& Kim, J. (2015). A bi-layer TiO2 photoanode for highly durable, flexible dyesensitized solar cells. Journal of Materials Chemistry A, 3 (8), 4679-4686. Journal of Materials Chemistry A

\section{Authors}

Jianjian Lin, Yong Peng, Alexander Pascoe, Fuzhi Huang, Yi-Bing Cheng, Yoon-Uk Heo, Andrew Nattestad, Wanchul Seung, Sung Kyun Kim, Hoon Joon Yoon, Sang Woo Kim, Yusuke Yamauchi, S X. Dou, and Jung Ho Kim 


\section{ARTICLE}

Cite this: DOI: $10.1039 / \times 0 \times x 00000 x$

\section{Highly Connected Hierarchical Textured $\mathrm{TiO}_{2}$ Spheres as Photoanodes for Dye-sensitized Solar Cells}

Received 00th January 2012, Accepted 00th January 2012

DOI: $10.1039 / \times 0 \times x 00000 x$

www.rsc.org/
Jianjian Lin,,${ }^{a, b}$ Andrew Nattestad, ${ }^{* c}$ Hua Yu, ${ }^{b}$ Yang Bai, ${ }^{b}$ Yu Chen, ${ }^{b}$ Zheng Xing, ${ }^{b}$ Bei Wang, ${ }^{b}$ Lianzhou Wang, ${ }^{* b}$ Ziqi Sun, ${ }^{a}$ Jae-Geun Kim,,${ }^{a}$ Victor Malgras, ${ }^{a}$ Fargol Bijarbooneh, ${ }^{a}$ Shi Xue Dou, ${ }^{a}$ Jung Ho Kim, ${ }^{* a}$

\begin{abstract}
We present a new type of microstructured $\mathrm{TiO}_{2}$ sea urchin-like assembly, composed of high aspect-ratio nanosheets. We also demonstrate the applicability of these structures as photoanodes in dye-sensitized solar cells, with $9.0 \%$ conversion efficiency realized, a considerable improvement from commercial Dyesol paste $(8.2 \%)$ under the same conditions. We reveal that this new $\mathrm{TiO}_{2}$ nanostructure is beneficial to the enhanced dye loading and the efficient light scattering. In particular, the interpenetrating individual sheets of the spheres result in more intimate interparticle connections and providing efficient electron transfer pathways.
\end{abstract}

\section{Introduction}

Dye-sensitized electrochemical photovoltaic cell technology has been recognized as a viable option for power generation. ${ }^{1}$ Dyesensitized Solar Cells (DSCs) have attracted much attention over the past two decades on account of features, such as shorter energy payback time, lower dependence on the angle of incidence of light, insensitivity to temperature changes, easy fabrication on rigid and flexible substrates, and relatively high energy conversion efficiency. $^{2-5}$ One of the core components in the DSC system is usually a wide-band-gap titanium oxide $\left(\mathrm{TiO}_{2}\right)$ thin film that serves as a support for the dye molecules and as an electron-transporting medium. Typically, in the photoanode, insufficient electron diffusion coefficient in electrodes composed of nanometer-sized $\mathrm{TiO}_{2}$ particles is believed to limit the power conversion efficiency. This is because electron collection is determined by trapping/detrapping events at the sites of the electron traps (defects, surface states, grain boundaries, self-trapping etc.). ${ }^{6}$ With this as motivation, there is an overwhelming desire among researchers to design and synthesize materials that simultaneously have large surface areas (to absorb more dye molecules), efficient light scattering capability, and faster electron transport. In addition, the pores formed in the $\mathrm{TiO}_{2}$ layer must be sufficiently large in size, with good connectivity for efficient diffusion of electrolyte components. ${ }^{7}$ One solution for this requirement is to use one-dimensional (1D) nanostructures, which can provide direct channels for the rapid collection of the photogenerated electrons, reduce charge recombination, and simultaneously enhance the electrolyte diffusion. ${ }^{8-12}$ However, the typical low surface area of the $1 \mathrm{D}$ nanostructures lead to reduced dye loading and hence reduced light harvesting, leading to lower photocurrents.

Alternatively, bi-layer structured nanoparticle films have been designed, to confine the incident light within the photoanode. ${ }^{13-18}$ Such a configuration, however, increases the thickness of the photoanode film, thus, photogenerated electrons at the light scattering layer have to be transported a longer distance within the photoelectrode film to reach the current collector electrode and therefore suffer from a high rate of recombination. Many groups have also tried to combine nanometer-sized particles with micrometer-sized particles to make full use of the combined size advantages. ${ }^{19-21}$ Most of these structures, however, were obtained on the basis of separate $\mathrm{TiO}_{2}$ materials with different morphologies, which unavoidably bring in tedious fabrication procedures. ${ }^{22}$

In this work, we introduce a novel material structure for use in DSC photoanodes, which consists of hierarchical assemblies of polycrystalline anatase $\mathrm{TiO}_{2}$ nanosheets and appear to resemble seaurchins. These spheres have a bimodal distribution of sizes, leading to both effective dye adsorption and light-scattering behavior, as well as enhanced electronic interconnectivity within the photoanode. An overall energy conversion efficiency of up to $9.0 \%$ can be achieved by using these highly connected hierarchical textured $\mathrm{TiO}_{2}$ spheres (HCHT) photoelectrode and N719 dye. 
HCHT was synthesized by hydrothermal treatment of a solution of titanium butoxide (TB) and acetic acid (HAc) followed subsequently by calcination at $500{ }^{\circ} \mathrm{C}$. Figs. 1(a, c) show scanning electron microscope (SEM) images of the desired product. The thin 2D nanosheets can be seen to be the building units of these larger structures, with an average thickness of approximately $10 \mathrm{~nm}$. These can be more clearly distinguished in Fig. 1 (d) and Fig. S1(c),
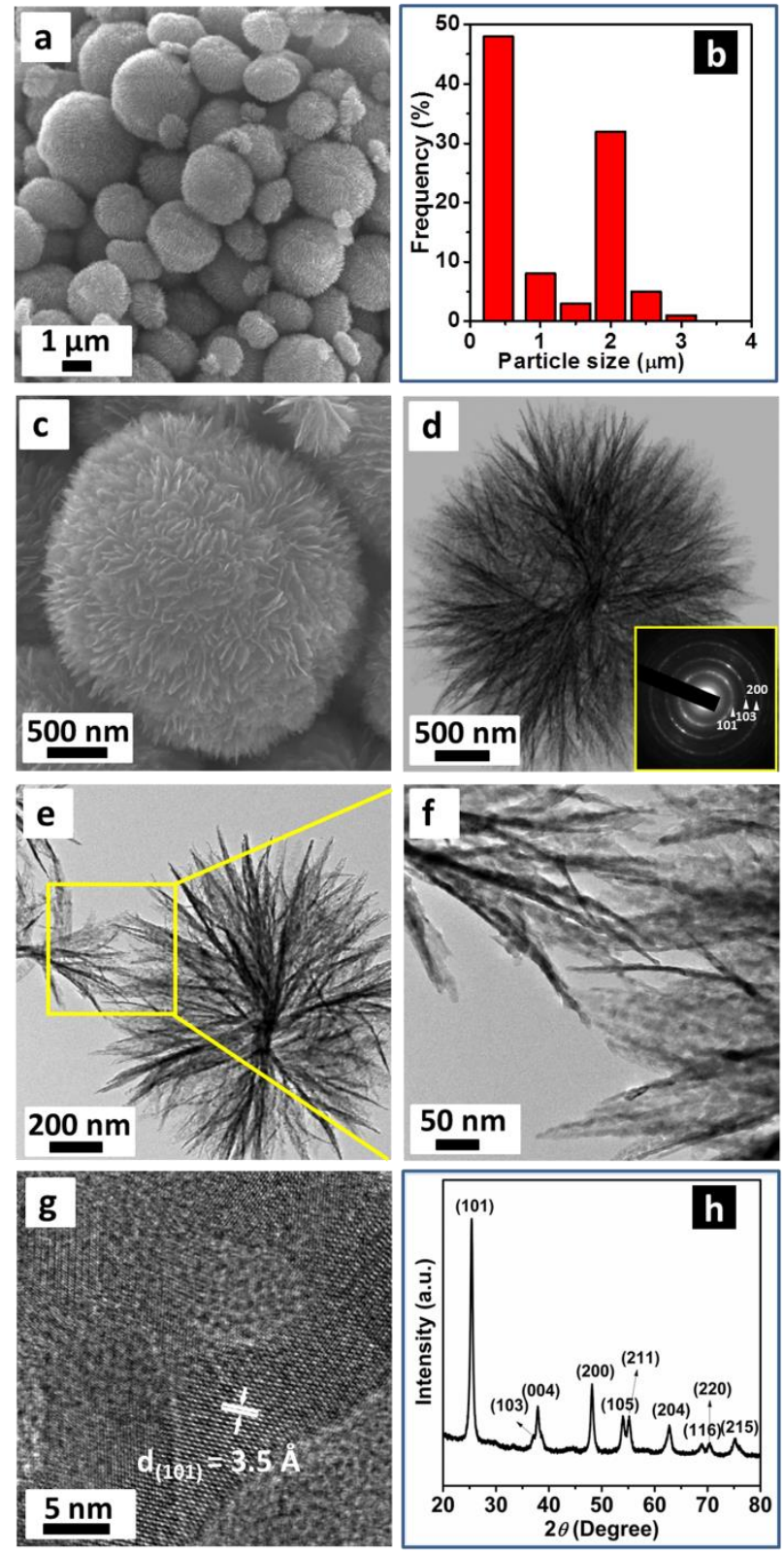

Fig. 1 Physical characterization of the calcined HCHT: (a) low magnification SEM; (b) particle size distribution, by calculation on 600 particles from Fig. S1(a) using the Image J software; (c) SEM image of an individual sphere; (d) bright-field TEM image visualizing the nanosheets building blocks, Inset: selected area electron diffraction (SAED) pattern of the whole sphere in (d); (e) TEM image of two typical interconnected spheres; (f) enlarged TEM image revealing details of the interconnection of nanosheets; (g) HRTEM image, showing the fringe spacing of anatase $\mathrm{TiO}_{2}$ nanocrystals; and (h) XRD pattern of the calcined $\mathrm{HCHT}$, indicating the $\mathrm{TiO}_{2}$ crystals with the tetragonal anatase phase (JCPDS No. 21-1272, $a=3.785 \AA, b=3.785 \AA, c=9.514 \AA$ ) after the calcination treatment, without any impurity phase. assembled into hierarchical spheres. Interestingly, the size distribution Fig. 1 (b) reveals a bimodal distribution centered at $c a$. 0.4 and $2.0 \mu \mathrm{m}$. The microstructure of the hierarchical spheres was directly observed by transmission electron microscopy (TEM). Interestingly, in the higher resolution images in Fig. 1(e, f), it can be seen that the nanosheets are perpendicular to the sphere surface and are interlocked with the nanosheets of neighboring spheres. We expect that this configuration would be efficient from the viewpoints of electron transfer. The small features, created by these sheets, also allow for high dye loading, a feature typically counterposed to effective light scattering. High resolution TEM (HRTEM) image [Fig. 1(g)] confirms that the calcined hierarchical $\mathrm{TiO}_{2}$ spheres are composed of crystalline $\mathrm{TiO}_{2}$ nanocrystals with a fringe spacing of approximately $3.5 \AA$, corresponding to the (101) plane of anatase phase. The related selected area electron diffraction (SAED) pattern in Fig. 1(d) also confirms the polycrystalline nature of the hierarchical spheres, with the three most distinct concentric diffraction rings moving outward from the center assigned to the (101), (103), and (200) planes of anatase $\mathrm{TiO}_{2}$, respectively. In addition, the successful preparation of anatase is further demonstrated by the X-ray diffraction (XRD) pattern [Fig. 1(h)] and the Raman spectrum [Fig. S1(e)].

The formation mechanism of such a nanosheet-based hierarchical structure can be understood by examining precipitates extracted at different stages of the reaction, as shown in Scheme 1. Based on TEM (Fig. S2), XRD (Fig. S3), and Fourier transform infrared spectroscopy (FTIR) characterizations (Fig. S4), it can be determined that the HAc does not fully react with the TB during the short reaction time of $1 \mathrm{~h}$. As such and the sample generates agglomerated nanocrystals [Fig. S2(a)]. The presence of the asymmetric and symmetric stretching vibrations of the carboxylic groups centered at 1566, 1452, and $1421 \mathrm{~cm}^{-1}$ [Fig. S4(b)] reveal the coordination of the HAc to the titanium centres, ${ }^{28,} 29$ indicating the formation of a titanium-containing intermediate (Fig. S3). With an extended reaction time $(5 \mathrm{~h})$, the Ti-complex intermediates

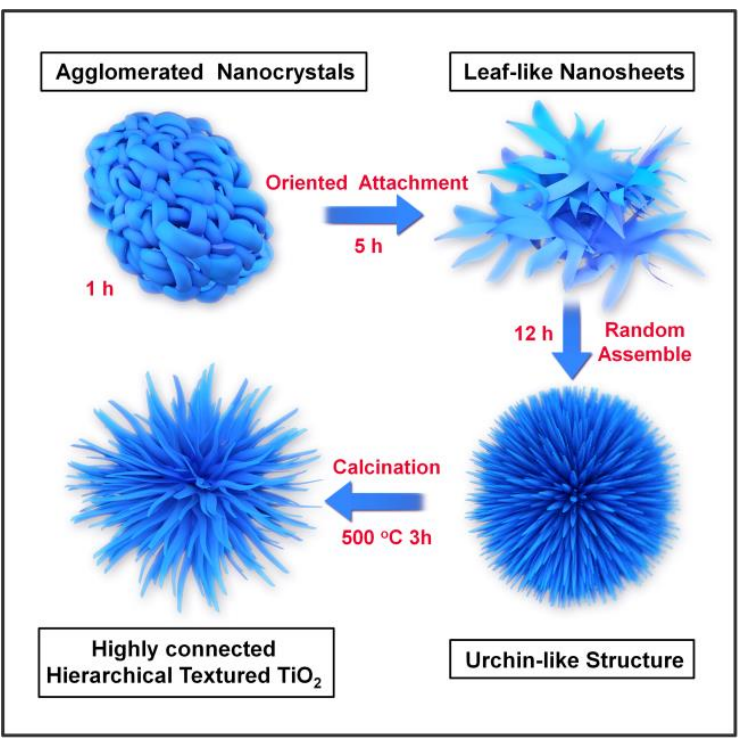

Scheme 1. Schematic diagram of the formation process of HCHT. 
assembled to from leaf-like nanosheets through an oriented attachment process, to bear some resemblance to the HCHT particles [Fig. S2(b)]. This was however, only seen to be fully complete after $12 \mathrm{~h}$, with urchin-like structures [Fig. S2(c)]. It is noted that XRD of these structures (Fig. S3) reveals that this material still has low crystallinity. Calcination is required to obtain the highly crystalline material, from the decomposition of the as-prepared Ti-complex intermediate spheres to $\mathrm{TiO}_{2}$.

The formation of the leaf-like nanosheets is concluded to occur via the following mechanism: acidolysis of TB is catalyzed by HAc through the formation of a Ti-acetate complex. Evidence of this TBHAc complex is seen with FTIR [Fig. S4(a, b)], ${ }^{30}$ with a weak band at $1721 \mathrm{~cm}^{-1}$ corresponding to the stretching vibration of the $\mathrm{C}=\mathrm{O}$ group of HAc. In comparison with pure TB and HAc, new bands are observed at $3426,1566,1452,1421$, and $1259 \mathrm{~cm}^{-1}$. It is well known that acetate ligands are produced by the reaction of TB with HAc and have several modes of coordination, including monodentate and bidentate (chelating and bridging). ${ }^{31-33}$ The alcohol $n \mathrm{C}_{4} \mathrm{H}_{9} \mathrm{OH}$ is also generated as a by-product in the formation process of these acetate ligands. The peak at $3426 \mathrm{~cm}^{-1}$, (observed for all intermediates), should be assigned to the stretching vibration of the hydroxyl groups on $n \mathrm{C}_{4} \mathrm{H}_{9} \mathrm{OH} .{ }^{34}$ Moreover, the separation $\left(\Delta v=140 \mathrm{~cm}^{-1}\right)$ between 1566 and $1426 \mathrm{~cm}^{-1}$ suggests that some acetate groups act as bridging ligands between two titanium atoms. ${ }^{31-33}$ According to a previous report, ${ }^{31}$ the $\Delta v$, for the latter possibility will be higher than $150 \mathrm{~cm}^{-1}$. The presence of the $1721 \mathrm{~cm}^{-1}(\mathrm{C}=\mathrm{O})$ band can be attributed to the contribution of monodentate-coordinated acetates, while the weak absorption indicates the small amount of such monodentate-coordinated acetates, so that, it can be concluded that most of the Ti-acetate complexes are bidentate-coordinated acetates. Through the acidolysis process, the nascent $\mathrm{TiO}_{2}$ nanocrystals are surrounded by numerous bidentate-coordinated acetates. Given the direction of the $\pi-\pi$ interactions, the amorphous leaf-like nanosheets are constructed by the oriented aggregation of these $\mathrm{TiO}_{2}$ nanocrystals. ${ }^{30}$ In addition, thermogravimetric analysis (TGA) of the as-prepared precipitates, measured under flowing air (Fig. S5), indicates that a considerable amount of $n \mathrm{C}_{4} \mathrm{H}_{9} \mathrm{OH}(\sim 29 \mathrm{wt} \%)$ was trapped inside the Ti-complex intermediate spheres, and the complete decomposition of the organics occurred at approximately $400{ }^{\circ} \mathrm{C} .{ }^{31}$ Above $400{ }^{\circ} \mathrm{C}$, the weight of the sample remains almost constant. The sharp peak in the differential scanning calorimetry (Fig. S5) curve, starting at $350{ }^{\circ} \mathrm{C}$, approximately, corresponds to the crystallization of the amorphous residue into anatase. Therefore, it can be postulated that the synthesized sample after calcination at 400 ${ }^{\circ} \mathrm{C}$ is pure $\mathrm{TiO}_{2}$ without any organic impurities. Finally, calcination at $500{ }^{\circ} \mathrm{C}$ for $3 \mathrm{~h}$ resulted in the formation of pure HCHT, as shown in Fig. 1.

Nitrogen adsorption-desorption measurements were performed to obtain the Brunauer-Emmett-Teller (BET) specific surface area, porosity, and pore size distribution for the Dyesol [NR 18T transparent (hereafter, Dyesol-T) and WER-02 scattering (Dyesol-S) ] and HCHT materials. As observed in Fig. 2(a), the isotherm of the HCHT appears to be a Type IV curve with an H3 hysteresis, which is usually ascribed to slit-like mesopores formed by sheet-like particles. ${ }^{23}$ The two hysteresis loops in the isotherm suggest that hierarchical nanoporous structures exist within the matrix, which can
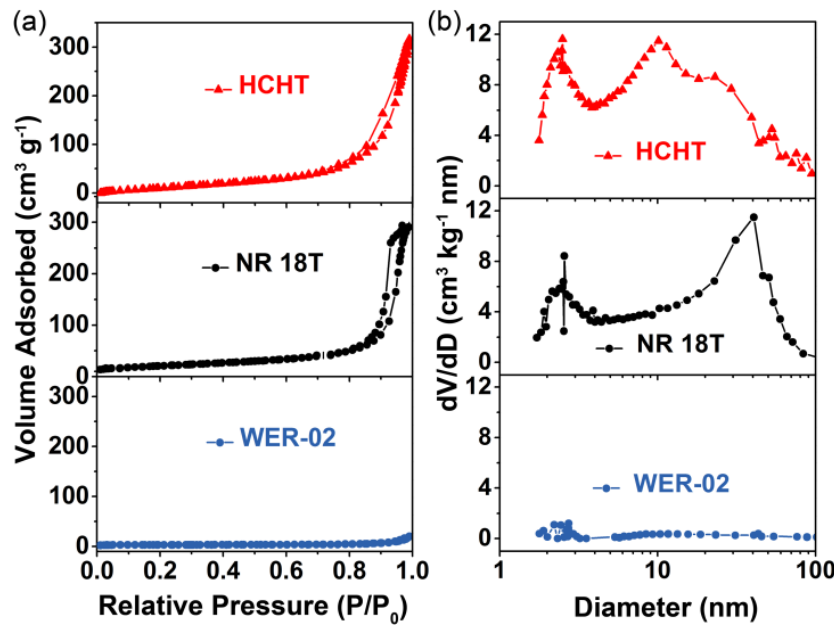

Fig. 2. (a) $\mathrm{N}_{2}$ adsorption-desorption isotherms of the Dyesol-scattering layer (Dyesol-S, WER-02, black closed circles), the Dyesol-transparent layer (Dyesol-T, NR18T, black closed circles) and the HCHT (red closed triangles); and (b) corresponding pore size distributions calculated by the BarrettJoyner-Halenda (BJH) method from the adsorption branch. Before BET measurements, all the particles were dried and then calcined at $500{ }^{\circ} \mathrm{C}$ for 3 h.

be directly verified by the pore size distribution plot in Fig. 2(b) (determined by BJH analysis). The pore size distribution of the HCHT ranges between 2 and $100 \mathrm{~nm}$, with a bimodal pore size distribution centered at $2.5 \mathrm{~nm}$ and $10 \mathrm{~nm}$ (as might be expected given the hierarchical structure). Interestingly, the mean average pore diameter is $17.6 \mathrm{~nm}$ due to large mesopores with diameters of more than $10 \mathrm{~nm}$, accounting for the majority of the slit-like mesopores, which result from the gaps between the randomly assembled nanosheets and can be seen clearly in Fig. S1(b). ${ }^{24}$ In addition, the voids formed by aggregated spheres may also contribute to the large pores [Fig. 1(a)]. ${ }^{25}$ It is well known that the pores formed in the $\mathrm{TiO}_{2}$ layer must be sufficiently large in size with excellent mutual connectivity for the efficient diffusion of electrolyte; ${ }^{7}$ As such, larger pores (between spheres) in HCHT can serve as a "highways" for efficient electrolyte diffusion. The data of BET specific surface areas, porosities and roughness factors for the Dyesol-S, Dyesol-T, and HCHT are summarized in Table 1. The data shows that the HCHT film has a larger surface area and higher porosity than the Dyesol film, indicating that HCHT has higher dye adsorption capability. The approximately 1.3 times higher roughness

Table 1 Specific surface area, porosity, and roughness factor of Dyesol and HCHT materials.

\begin{tabular}{crrr}
\hline Samples & $\begin{array}{c}\text { Specific surface } \\
\text { area }\left(\mathrm{m}^{2} \mathrm{~g}^{-1}\right)\end{array}$ & Porosity ${ }^{\mathrm{a})}(\%)$ & $\begin{array}{c}\text { Roughness factor } \\
\left(\mu \mathrm{m}^{-1}\right)\end{array}$ \\
\hline Dyesol-S & 10 & 9.82 & 35.2 \\
Dyesol-T & 74 & 64.2 & 103.3 \\
HCHT & 103 & 66.9 & 133.0 \\
\hline
\end{tabular}

a) The porosities (P) of Dyesol-S, Dyesol-T and HCHT were calculated according to: $\mathrm{P}=\mathrm{V}_{p} /\left(\mathrm{\rho}^{-1}+\mathrm{V}_{p}\right)$, where $\mathrm{V}_{p}$ is the specific cumulative pore volume $\left(\mathrm{cm}^{3} \mathrm{~g}^{-1}\right)$ and $\rho^{-1}$ is the inverse of the density of anatase $\mathrm{TiO}_{2}\left(\rho^{-1}=\right.$ $\left.0.257 \mathrm{~cm}^{3} \mathrm{~g}^{-1}\right) .^{26}$

b) An estimation of the roughness factor (R) per unit film thickness of the films is obtained by $R=\rho(1-P) S$, where $\rho$ is the density $\left(\mathrm{g} \mathrm{cm}^{-3}\right)$ of anatase $\mathrm{TiO}_{2}, \mathrm{P}$ is the porosity (\%) of the film, and $\mathrm{S}$ is the specific surface area $\left(\mathrm{m}^{2}\right.$ $\left.\mathrm{g}^{-1}\right) \cdot{ }^{27}$ 
factor in the HCHT film leads to an increase in the light harvesting efficiency from the larger amount of dye adsorption, which will be further discussed below.

The HCHT was applied in photoanodes of DSCs. The thickness of the film derived from the spheres was around $15 \mu \mathrm{m}$. The morphology of the spherical $\mathrm{TiO}_{2}$ structures is clearly seen in the film prepared from HCHT [shown in inset of Fig. 3 and Fig. S6(a)]. For comparison, a Dyesol-based film with double layers [12 $\mu \mathrm{m}$ transparent layer (Dyesol-T) $+4 \mu \mathrm{m}$ scattering layer (Dyesol-S)] was prepared under analogous conditions (see SI). Fig. 3 shows the current density-voltage $(J-V)$ characteristics of the Dyesol-based and HCHT-based DSCs. As listed in Table 2, the Dyesol-based DSCs showed an open-circuit photovoltage $\left(V_{\mathrm{oc}}\right)$ of $0.805 \mathrm{~V}$, a short-circuit photocurrent density $\left(J_{\mathrm{sc}}\right)$ of $14.3 \mathrm{~mA} \mathrm{~cm} \mathrm{~cm}^{-2}$, and an energy conversion efficiency $(\eta)$ of $8.2 \%$, while the HCHT-based DSCs showed a $V_{\text {oc }}$ of $0.850 \mathrm{~V}$, a $J_{\text {sc }}$ of $17.1 \mathrm{~mA} \mathrm{~cm}^{-2}$, and an $\eta$ of $9.0 \%$ under one sun conditions, resulting in a $19.6 \%$ and $6 \%$ increase in $J_{\text {sc }}$ and $V_{\text {oc }}$, respectively. The remarkable increase in $J_{\text {sc }}$ is probably attributable to the larger surface area due to the hierarchical and mesoporous morphology of the HCHT photoanode, allowing it to take up more dye molecules $\left(6.2 \times 10^{-7} \mathrm{~mol} \mathrm{~cm}^{-2}\right)$, in tandem with light scattering (discussed in more details below).

To quantify dye loading, N719 stained films were exposed to a basic $0.1 \mathrm{M} \mathrm{NaOH}$ solution and the amount of desorbed dye molecules was examined by ultraviolet-visible (UV-Vis) spectroscopy [shown in Fig. S6(b)]. The absorption spectrum of the desorbed dye represents the amount of dye adsorbed at the photoanode. Tow spectra show two peaks at $378 \mathrm{~nm}$ and $512 \mathrm{~nm}$, which are blue-shifted from the original N719 dye absorption peaks. The blue shift typically occurs in alkaline solutions. ${ }^{35}$ In general, as the amount of dye adsorption increases, more light can be harvested, hence a larger photocurrent density. ${ }^{36}$ The amount of adsorbed dye for the HCHT photoanode $\left(6.2 \times 10^{-7} \mathrm{~mol} \mathrm{~cm} \mathrm{~cm}^{-2}\right)$ is significantly higher than for the Dyesol photoanode $\left(3.9 \times 10^{-7} \mathrm{~mol} \mathrm{~cm}^{-2}\right)$, which may contribute to the remarkably improved $J_{\mathrm{sc}}$ for the HCHT-based DSCs.

Even if the dark current cannot be directly related to the back

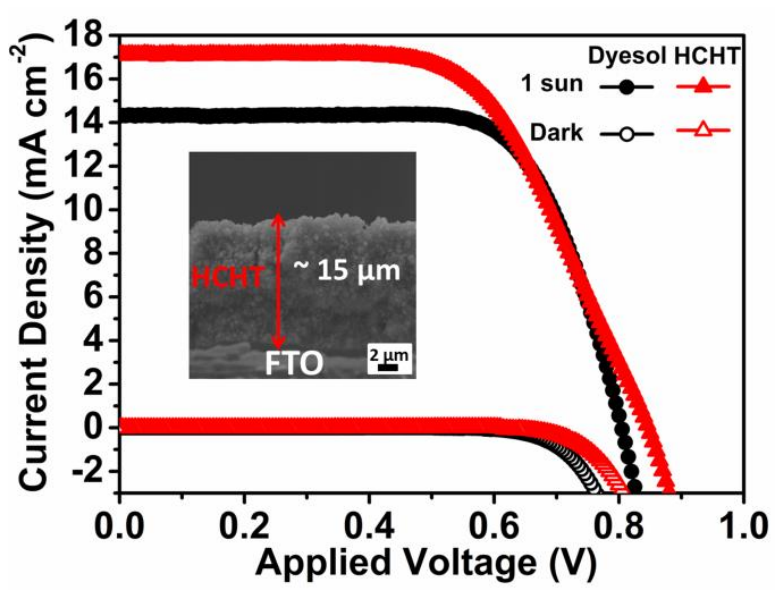

Fig. 3. $J-V$ characteristics of Dyesol- and HCHT-based DSCs. Illumination intensity of $100 \mathrm{~mW} \mathrm{~cm}-2$ with AM 1.5 and active area of $0.16 \mathrm{~cm}^{2}$ were applied. Inset is the SEM cross-sectional image of the nanosheet-based highly connected hierarchical anatase $\mathrm{TiO}_{2}$ sphere film on the fluorine-doped tin oxide (FTO) layer, with the film applied by the doctor blade method.
Table 2 Detailed photovoltaic parameters of cells based on Dyesol and HCHT photoanodes measured under air mass (AM) 1.5 global (1.5G) one

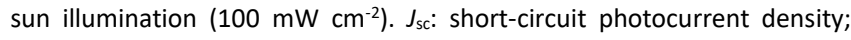

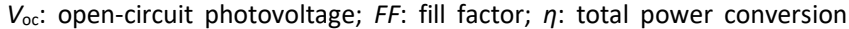
efficiency. The active areas were $\sim 0.16 \mathrm{~cm}^{2}$ for all of the cells (with the mask area $0.25 \mathrm{~cm}^{2}$ ), and the data presented are average values obtained after testing four cells.

\begin{tabular}{ccccccc} 
Samples & $\begin{array}{c}J_{\mathrm{sc}} \\
(\mathrm{mA}\end{array}$ & $\begin{array}{c}V_{\mathrm{oc}} \\
(\mathrm{V})\end{array}$ & $\begin{array}{c}F F \\
(\%)\end{array}$ & $\begin{array}{c}\eta \\
(\%)\end{array}$ & $\begin{array}{c}\text { Amount of dye } \\
\left(10^{-7} \mathrm{~mol} \mathrm{~cm}^{-2}\right)\end{array}$ & $\begin{array}{c}\text { Film } \\
\text { thickness }) \\
(\mu \mathrm{m})\end{array}$ \\
\hline Dyesol & 14.3 & 0.805 & 71.0 & 8.2 & $3.9 \pm 0.1$ & $16 \pm 0.3$ \\
& \pm 0.2 & \pm 0.01 & \pm 2 & \pm 0.2 & & \\
HCHT & 17.1 & 0.850 & 62.0 & 9.0 & $6.2 \pm 0.1$ & $15 \pm 0.5$ \\
& \pm 0.5 & \pm 0.02 & \pm 2 & \pm 0.2 & &
\end{tabular}

a) The dye-immersed electrodes were soaked in a $0.1 \mathrm{M}$ alkaline solution in ethanol and water to desorb the dye from the electrodes. The amount of desorbed dye was quantified by measuring its optical absorption spectrum.

b) Measurement of film thickness was carried out on a surface profile system (Veeco Dektak 150).

electron transfer process, since the electrolyte concentration in the films and the potential distribution across the nanoporous electrode in dark current are different from those under illumination, it has been considered as a qualitative technique to describe the extent of the back electron transfer. ${ }^{37}$ Furthermore, dark $J$ - $V$ curves show the dark current onset of HCHT-based DSC has shifted to a higher potential and produced a smaller dark current at the same potential above $0.7 \mathrm{~V}$. These observations reflect a lower recombination rate between transferred electrons and $\mathrm{I}_{3}{ }^{-}$ions for the HCHT.

To investigate the scattering efficiency of the Dyesol and HCHT films, the reflectivity of each film was studied. The inset in Fig. 4 shows the diffuse reflectance spectra of the Dyesol-S (WER02) film and the HCHT film. Both films show high diffuse reflection capability across most of the visible spectrum. Diffuse reflectivity is observed to be lower for the Dyesol-S film for wavelengths above $600 \mathrm{~nm}$ to $800 \mathrm{~nm}$, which is actually the region in which diffuse reflectivity is most critical, as the extinction co-efficient of the dye (N719) is comparatively low. The HCHT film scattering this light more effectively gave it a higher probability of being absorbed. Films produced from the HCHT show superior diffuse reflection capabilities for longer wavelengths $(600-800 \mathrm{~nm})$ due to the larger particle size, which is comparable to the wavelength of the incident light in question.

Fig. 4 displays the wavelength distribution of the incident monochromatic photon to current conversion efficiency (IPCE) for both Dyesol and HCHT films. The IPCE is determined by the light absorption efficiency of the dye, the quantum yield of electron injection, and the efficiency with which electrons are collected at the conducting glas s substrate, which is strongly affected by the morphology and surface area of the photoelectrode. Both films result in reasonably broad IPCE response, however, the HCHT film is higher across the whole spectra. Closer analysis (Fig. S7) reveals the enhancement in IPCE to be most marked at $\lambda>650 \mathrm{~nm}$. In the shortwavelength spectral region $(400-450 \mathrm{~nm})$, the IPCE of the Dyesol film is about $8 \%$ lower than that of the HCHT film. In this spectral region, iodide species $\left(\mathrm{I}_{3}{ }^{-}\right)$in the electrolyte absorb strongly, attenuating the amount of light reaching the sensitizing dye and thus limiting the photocurrent. At the maximum value of the IPCE 


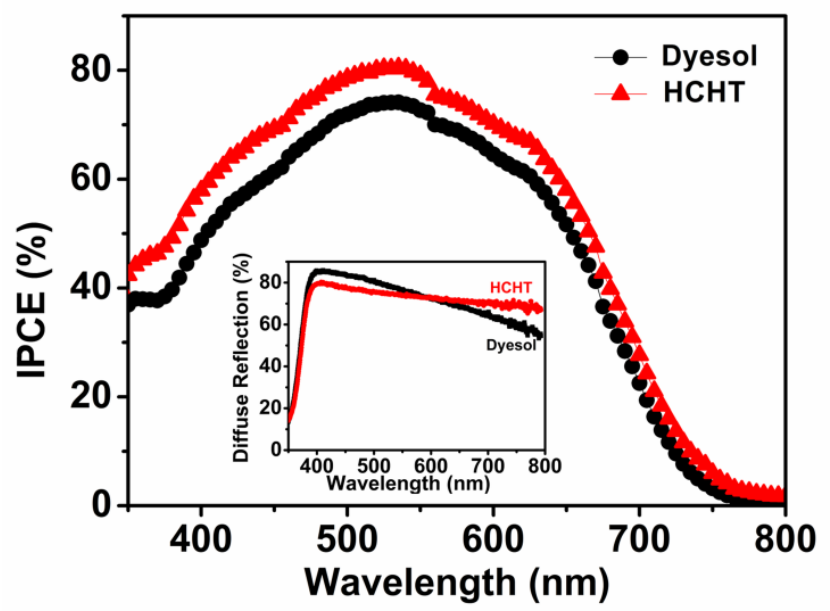

Fig. 4. Incident photon to current conversion efficiency (IPCE) curves of Dyesol-based (12 $\mu \mathrm{m}$ transparent layer $+4 \mu \mathrm{m}$ scattering layer film) and HCHT-based (15 $\mu \mathrm{m}$ film) DSCs; inset: diffuse reflectance spectra of the Dyesol and HCHT films.

spectra at $535 \mathrm{~nm}$, the IPCE of the HCHT film is approximately $6 \%$ higher than that of the Dyesol film.

In order to study the interfacial reactions of photoexcited electrons and better understand the kinetics of electrochemical and photoelectrochemical processes occurring in DSCs operations, electrochemical impedance spectroscopy (EIS) was performed. ${ }^{38-41}$ Fig. 5(a) presents the Nyquist plots of the impedance spectra obtained under one sun illumination for DSCs assembled with the

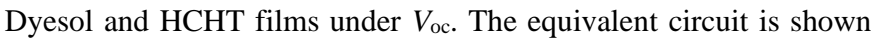
as the inset and the fitting data is shown in Fig. S8 and Table S2. In general, three semicircles extending from the total series resistance $\left(R_{\mathrm{S}}\right)$ can be recognized and fitted according to an equivalent circuit model, where the finite diffusion element is also represented by the shunt resistance and low frequency constant phase element (CPE). The semicircle in the high frequency region represents the impedance corresponding to charge transfer at the counter electrode $\left(R_{\mathrm{ct} 1}\right)$, while those at intermediate frequency and low-frequency give information on the impedance at the $\mathrm{TiO}_{2} /$ electrolyte interface $\left(R_{\mathrm{ct} 2}\right)$ related to the charge transport/recombination and the finite diffusion of the electrolyte ( $R_{\text {diff }}$ ), respectively. ${ }^{39,}{ }^{41-43}$ According to the approach of Adachi et al., ${ }^{44}$ several parameters related to the properties of electron transport in the semiconductor can be deduced from the Nyquist plot. In particular, the charge transfer (recombination) resistance $\left(R_{\mathrm{ct} 2}\right)$ related to electron-hole recombination can be determined from the central arc diameter. In our case, it was found that the recombination resistance at the $\mathrm{TiO}_{2} /$ dye/electrolyte interface $\left(R_{\mathrm{ct} 2}\right)$ for HCHT was smaller than for the devices made using the commercial paste, which indicates electrons are easier to move at the HCHT surface and contribute to the charge transport at the photoanode. The Bode phase plots shown in Fig. 5(b) likewise support the differences in the electron lifetime for the $\mathrm{TiO}_{2}$ films derived from Dyesol and HCHT. Three main frequency peaks are observed. These peaks correspond to the charge transfer processes at different interfaces within the DSCs. Interestingly, the maximum frequency in the intermediate frequency regime, which is related to electron transfer in the HCHT-based film), is lower than that for the Dyesol-based film. According to the EIS model developed by Kern et al., ${ }^{45}$ the electron lifetime ( $\left.\tau_{\mathrm{eff}}\right)$ of injected electrons in a $\mathrm{TiO}_{2}$ film can be calculated from the low frequency results as:

$$
\tau_{\text {eff }}=\frac{1}{2 \pi f_{\text {max }}}
$$

where the characteristic $f_{\max }$ is the maximum frequency in the midfrequency peak. The middle-frequency peak of the Dyesol particle containing DSC is at a higher frequency compared to the HCHTbased DSC, indicating a longer lifetime for the HCHT. Longer electron lifetimes are observed for HCHT-sensitized solar cells, indicating more effective suppression of the back-reaction of the injected electrons with the $\mathrm{I}_{3}{ }^{-}$ions in the electrolyte.

To summarize, based on the above characterizations, HCHT particles have several functions particularly well suited for application in DSCs. This is shown in Scheme 2. The feature of the sheet-like building blocks results in a high active surface
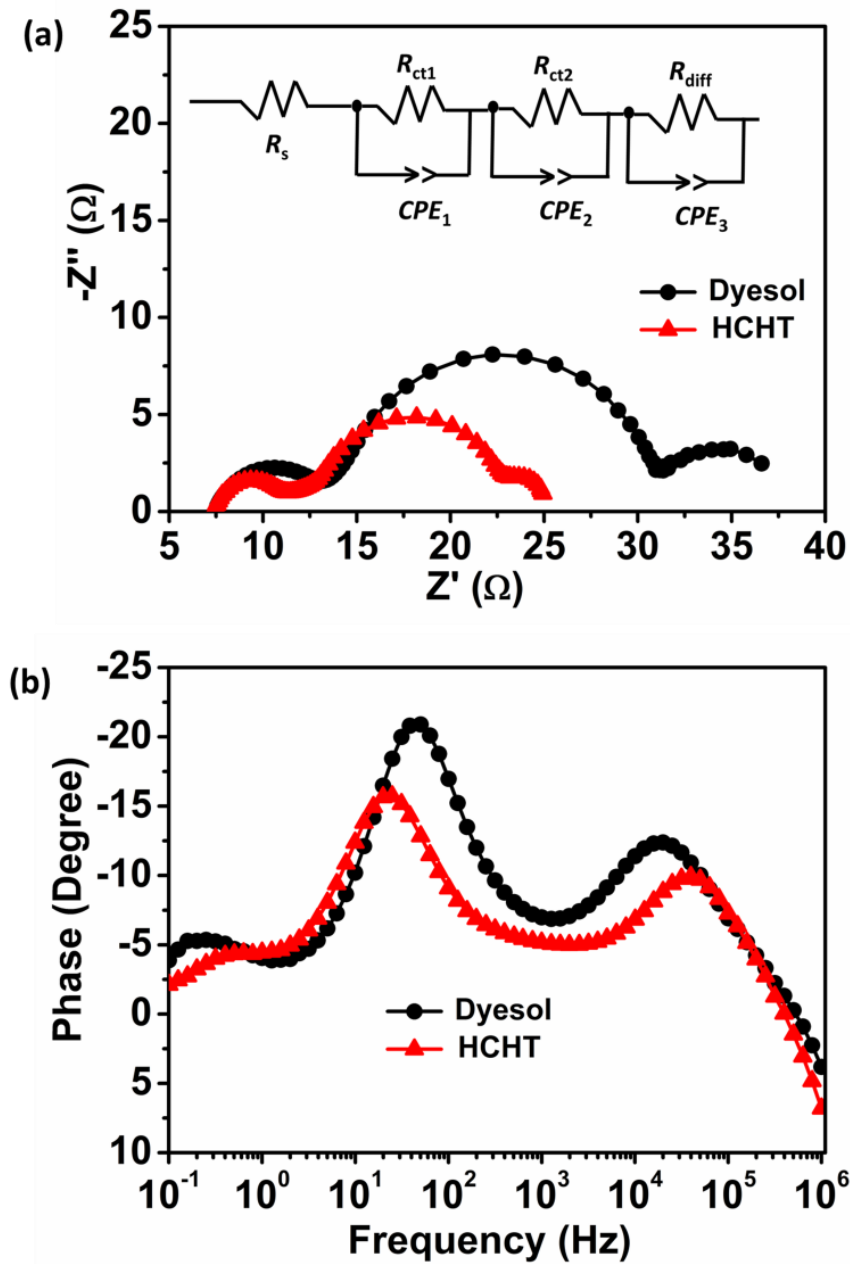

Fig. 5 Impedance spectra of DSCs containing Dyesol and HCHT photoanodes measured at $V_{\text {oc }}$ under illumination of $100 \mathrm{~mW} \mathrm{~cm}^{-2}$ : (a) Nyquist plots, with the inset showing the equivalent circuit and the zoom part of the first semicircle, and (b) Bode phase plots. 


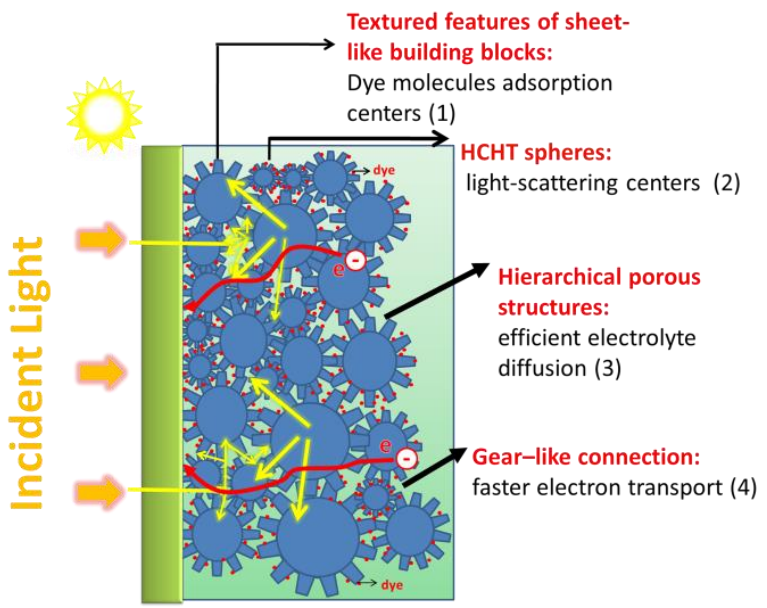

Scheme 2 Schematic illustration of photoanode structure with four functions.

area, which, in turn, allows for improved dye loading (1). Concurrently the spheres formed by these sheets are effective light-scattering centers across a broad range of incident wavelengths (2). Because of the bimodal pore size distribution, the large external pores can serve as a "highways" for efficient electrolyte diffusion (3). Finally, the overlapping and interconnected 2D nanosheets provide improved conduction pathways for electron transfer (4).

\section{Conclusions}

A new type of highly connected hierarchical textured $\mathrm{TiO}_{2}$ spheres (HCHT) was successfully synthesized by a facile hydrothermal process. The HCHT with well-defined mesopores simultaneously possesses high specific surface area, a pronounced light-scattering effect (especially $\lambda>600 \mathrm{~nm}$ ), and fast electron transport. The DSCs made from HCHT exhibit higher energy conversion efficiency of $9.0 \%$, compared to $8.2 \%$ for the commercial Dyesol $\mathrm{TiO}_{2}$ double layer photoanode.

\section{Acknowledgements}

The work is supported by an Australian Research Council Discovery Projects. Dr. Andrew Nattestad would like to thank the Australian Renewable Energy Agency (ARENA) for financial support. The authors would also like to thank the Australian National Fabrication Facility (ANFF) for access to equipment.

\section{Notes and references}

a Institute for Superconducting and Electronic Materials (ISEM), Faculty of Engineering, University of Wollongong, NSW 2522, Australia. E-mail: jhk@uow.edu.au

b ARC Centre of Excellence for Functional Nanomaterials, School of Chemical Engineering and Australian Institute for Bioengineering and Nanotechnology, The University of Queensland, Brisbane, QLD 4072, Australia. E-mail: 1.wang@uq.edu.au

c Intelligent Polymer Research Institute, University of Wollongong, NSW 2522, Australia. E-mail: anattest@uow.edu.au
1. M. Gratzel, Nature, 2001, 414, 338-344.

2. B. Oregan and M. Gratzel, Nature, 1991, 353, 737-740.

3. A. Yella, H. W. Lee, H. N. Tsao, C. Y. Yi, A. K. Chandiran, M. K. Nazeeruddin, E. W. G. Diau, C. Y. Yeh, S. M. Zakeeruddin and M. Gratzel, Science, 2011, 334, 629-634.

4. H. S. Kim, C. R. Lee, J. H. Im, K. B. Lee, T. Moehl, A. Marchioro, S. J. Moon, R. Humphry-Baker, J. H. Yum, J. E. Moser, M. Gratzel and N. G. Park, Sci. Rep., 2012, 2. 591.

5. J. Burschka, N. Pellet, S. J. Moon, R. Humphry-Baker, P. Gao, M. K. Nazeeruddin and M. Gratzel, Nature, 2013, 499, 316-319.

6. Y. C. Park, Y. J. Chang, B. G. Kum, E. H. Kong, J. Y. Son, Y. S. Kwon, T. Park and H. M. Jang, J. Mater. Chem., 2011, 21, 9582-9586.

7. Y. J. Kim, M. H. Lee, H. J. Kim, G. Lim, Y. S. Choi, N.-G. Park, K. Kim and W. I. Lee, Adv. Mater., 2009, 21, 3668-3673.

8. K. Zhu, N. R. Neale, A. Miedaner and A. J. Frank, Nano Lett., 2007, 7, 69-74.

9. G. K. Mor, K. Shankar, M. Paulose, O. K. Varghese and C. A. Grimes, Nano Lett., 2006, 6, 215-218.

10. C. Y. Lin, Y. H. Lai, H. W. Chen, J. G. Chen, C. W. Kung, R. Vittal and K. C. Ho, Energy Environ. Sci., 2011, 4, 3448-3455.

11. Y. L. Wang, M. Guo, M. Zhang and X. D. Wang, CrystEngComm, 2010, 12, 4024-4027.

12. M. Law, L. E. Greene, J. C. Johnson, R. Saykally and P. Yang, Nature Materials, 2005, 4, 455-459.

13. S. Ito, T. N. Murakami, P. Comte, P. Liska, C. Gratzel, M. K. Nazeeruddin and M. Gratzel, Thin Solid Films, 2008, 516, 4613-4619.

14. X. H. Miao, K. Pan, Y. P. Liao, W. Zhou, Q. J. Pan, G. H. Tian and G. F. Wang, J. Mater. Chem. A, 2013, 1, 9853-9861.

15. X. H. Sun, Y. M. Liu, Q. D. Tai, B. L. Chen, T. Peng, N. Huang, S. Xu, T. Y. Peng and X. Z. Zhao, J. Phys. Chem. C, 2012, 116, $11859-11866$.

16. Z. P. Zhang, S. Ito, B. O'Regan, D. B. Kuang, S. M. Zakeeruddin, P. Liska, R. Charvet, P. Comte, M. K. Nazeeruddin, P. Pechy, R. Humphry-Baker, T. Koyanagi, T. Mizuno and M. Gratzel, Z. Phys. Chemie-Int. J. Res. Phys. Chem. Chem. Phys., 2007, 221, 319-327.

17. L. Zhao, J. Li, Y. Shi, S. M. Wang, J. H. Hu, B. H. Dong, H. B. Lu and P. Wang, J. Alloy. Compd., 2013, 575, 168-173.

18. X. Wu, G. Q. Lu and L. Z. Wang, Energy Environ. Sci., 2011, 4, 3565-3572.

19. Z. S. Wang, H. Kawauchi, T. Kashima and H. Arakawa, Coord. Chem. Rev., 2004, 248, 1381-1389.

20. C. J. Barbe, F. Arendse, P. Comte, M. Jirousek, F. Lenzmann, V. Shklover and M. Gratzel, J. Am. Ceram. Soc., 1997, 80, $3157-$ 3171.

21. L. Yang, Y. Lin, J. G. Jia, X. R. Xiao, X. P. Li and X. W. Zhou, J. Power Sources, 2008, 182, 370-376.

22. V. Suryanarayanan, K. M. Lee, J. G. Chen and K. C. Ho, J. Electroanal. Chem., 2009, 633, 146-152.

23. M. Kruk and M. Jaroniec, Chem. Mat., 2001, 13, 3169-3183.

24. W. Yang, J. Li, Y. Wang, F. Zhu, W. Shi, F. Wan and D. Xu, Chem. Commun., 2011, 47, 1809-1811.

25. J. Jiang, F. Gu, W. Shao and C. Z. Li, Ind. Eng. Chem. Res., 2012, 51, 2838-2845.

26. J. van de Lagemaat, K. D. Benkstein and A. J. Frank, J. Phys. Chem. B, 2001, 105, 12433-12436.

27. K. D. Benkstein, N. Kopidakis, J. van de Lagemaat, A. J. Frank, J. Phys. Chem. B, 2003, 107, 7759.

28. Z. H. Zhang, X. H. Zhong, S. H. Liu, D. F. Li and M. Y. Han, Angew. Chem., Int. Ed., 2005, 44, 3466-3470.

29. D. Jiang, Y. Xu, B. Hou, D. Wu and Y. H. Sun, Eur. J. Inorg. Chem., 2008, 8, 1236-1240.

30. L. Li and C.-y. Liu, CrystEngComm, 2010, 12, 2073-2078.

31. S. Doeuff, M. Henry, C. Sanchez and J. Livage, J. Non-Cryst. Solids., 1987, 89, 206-216.

32. J. C. S. Wu, I. H. Teseng and W. C. Chang, J. Nanopart. Res., 2001, 3, 113-118.

33. Z. Zhang, X. Zhong, S. Liu, D. Li and M. Han, Angew. Chem. Int. Ed., 2005, 44, 3466-3470.

34. U. Hwang, H. Park and K. Koo, Ind. Eng. Chem. Res., 2004, 43, 728734. 
35. E. Palomares, R. Vilar and J. R. Durrant, Chem. Commun., 2004, 10, 362-363.

36. G. Schlichthorl, S. Y. Huang, J. Sprague and A. J. Frank, J. Phys. Chem. $B, 1997, \mathbf{1 0 1}, 8141-8155$.

37. S. Ito, P. Liska, P. Comte, R. L. Charvet, P. Pechy, U. Bach, L. Schmidt-Mende, S. M. Zakeeruddin, A. Kay, M. K. Nazeeruddin and M. Gratzel, Chem. Commun., 2005, 34, 43514353.

38. Q. Wang, J. E. Moser and M. Gratzel, J. Phys. Chem. B, 2005, 109, 1 4945-14953.

39. C. Longo, A. Nogueira, M.-A. De Paoli and H. Cachet, J. Phys. Chem. B, 2002, 106, 5925-5930.

40. Q. Wang, S. Ito and M. Gratzel, J. Phys. Chem. B, 2006, 110, 2521025221.

41. T. Hoshikawa, M. Yamada, R. Kikuchi and K. Eguchi, $J$. Electrochem. Soc., 2005, 152, E68-E73.

42. Y. Yoshida, S. Tokashiki, K. Kubota, R. Shiratuchi, Y. Yamaguchi, M. Kono and S. Hayase, Sol. Energy Mater. Sol. Cells, 2008, 92, 646-650.

43. L. Han, N. Koide, Y. Chiba and T. Mitate, Appl. Phys. Lett., 2004, 84, 2433-2435.

44. M. Adachi, M. Sakamoto, J. Jiu, Y. Ogata and S. Isoda, J. Phys. Chem. B, 2006, 110, 13872-13880.

45. R. Kern, R. Sastrawan, J. Ferber, R. Stangl, J. Luther, Electrochim. Acta, 2002, 47, 4213-42 